\title{
Evaluating the Effectiveness of Price Promotions
}

\author{
Ella Song
}

Suzhou Foreign Language School

\begin{abstract}
This paper looks at the effectiveness of price promotions on Amazon by considering the effect that they have on the sales rank of the promoted product. It also examines the link between the size and frequency of the price promotions. The paper uses data on 1,000 top-selling products from the 'shoes' category. It reaches three main conclusions. First, sales promotions improve product's sales rank, and the larger the sales promotion, the larger this improvement is. Second, the effects of the sales promotion tend to be permanent, i.e. the sales rank remains lower 30 days after the sales promotion take place. Third, the frequency of the sales promotions is inversely related with their sizes.
\end{abstract}

Keywords: Amazon; Economics; Retailing; Pricing strategy 


\section{Introduction}

Price promotions are used by many companies for introducing new products, increasing sales, or to influence the consumer decision process (Montaner \& Pina, 2008). Different types of price promotions are tailored to different types of goods and will exert positive or but sometimes also negative impact on the promoted brand.

Price promotions are generally used by companies to bring in consumers and drive revenues. The ultimate goal is always to increase profits. But there exist a number of ways to do so which would vary between different companies. First, sellers respond to their competitors' promotions by organizing their own promotions. Otherwise, they would be likely to lose consumers. Second, some retailers may use price incentives to increase the brand recognition. The consumers who are not familiar with the brand will not be willing to pay a lot for it, but they might give it a try if the price is sufficiently reduced. Third, some retailers use recurring promotional pricing to maintain ongoing purchases from price sensitive buyers. Finally, some price promotions serve the purpose of clearing the inventories. This is particularly prevalent in fashion as if the product is not sold by the end of the relevant season, it would be difficult to sell it at all. Therefore, it makes sense to reduce its price sufficiently to maximize profits.

Mulhern \& Padgett (1995) state that price promotions represent a major component of marketing strategies in retailing. Pricing is a process of foremost importance and complexity, as it must consider the consumers' preferences and the prospects of the companies. Notably, sales promotions constitute a significant part of all sales, which means that evaluating their effectiveness is highly important for the companies who organize them.

The reason why this paper focuses on Amazon is that it has 100 million subscribers worldwide and vast presence in the e-commerce market. Amazon has been referred to as "one of the most influential economic and cultural forces in the world". It is one of the most valuable online retailers in the world, so that results presented in this paper are based on a large sample and can therefore be considered representative for the broader e-commerce sector.

As mentioned, this essay aims to examine the effectiveness of price promotions on Amazon. Three hypotheses are proposed. Firstly, it is hypothesized that the sales ranks tend to drop when price promotions take place. The second hypothesis is that the sales rank would remain lower after the period of price promotions ends. The third hypothesis is that the larger the sales promotion, the less frequently would it take place. 


\section{Literature Review}

Waanders (2013) claims that price promotions can exert negative influence on certain aspects of the promoted brand, such as the perceived brand quality and brand image. As these aspects differ in high end brands and store brands, he hypothesizes that the effectiveness and consequences of deep price promotions would affect a store brand more negatively than a high-end brand. It is commonly assumed that a lower price is always associated with lower quality. In the case of food products, when a discount influences the perceived quality and brand image, it is also likely that the taste experience of the consumers is affected by the discount.

Waanders (2013) also evaluates the sales promotions' effectiveness. Products can be divided into having a utilitarian (bought for their practical use) or a hedonic (bought because of the pleasure, fun or enjoyment they can give) benefit. Sales promotions are more effective in influencing brand choices when the benefits sought in the product are coherent with the benefits of the sales promotion. Thus, a utilitarian sales promotion is more effective when it is used for a product with utilitarian features.

Moreover, sales promotions' effectiveness are also influenced by the characteristics of the deal. The most relevant one from the perspective of this paper is the depth of the promotion: if it is outside the latitude of price acceptance, consumers will see the price reduction as untrustworthy.

Finally, Waanders (2013) explains how the attribution theory makes consumers adapt their purchase frequency to the promotional pattern. This means buying a lot of product when it is on sale and then waiting until the product is promoted again. The lower price also relates to the anchoring and adjustment theory, which explains how people adapt their price expectations. The anchor-point of the consumer is changed based on the promoted price. Sales promotions do not only have negative consequence, but they are also used to develop brand awareness and brand image. Moreover, they can develop meaningful points of differences and unique associations.

Beltov, Jørgensen \& Zaccour (2006) propose a dynamic optimization model for a retailer's price promotions of two brands, focusing on three effects: 1) the immediate, and positive impact of a price deal on the sales of the promoted brand; 2) the effect of brand substitutions; and 3) the effect of consumers stockpiling the promoted brand during a deal period. The authors find that the smaller the discount on the brand, the more damaging the promotion of the brand will be for the current demand for the other brand. Secondly, they concluded that if a discount has a low impact on demand, the deal period is short and the stockpiling effect is large, then the discount should be smaller. Finally, they state that a forward-looking retailer should take into account the impacts 
of deals on future demand, thereby applying a smaller discount than a myopic retailer.

\section{Analysis}

\section{Data:}

The original data used in the analysis comes from Amazon.com and was collected via www.keepa.com data aggregator on $28^{\text {th }}$ of January 2020. The dataset contains information about 1000 top-selling products from the 'shoes' category. There are two reasons for why this specific data set is selected. Firstly, frequent and large sales promotions are common in the (more general) 'fashion' category, which gives us plenty of observations to test our hypothesis. Secondly, the choice of best-sellers was to make the sample selection process objective and independent of the potential biases of the researcher. The data comes in a panel format, which has the product dimension and the time dimension; data for each product is recorded for a period of time of varying length (between 204-2953 days), depending on how long the product has been offered on Amazon. The variables contained in this dataset are the date, the ASIS (unique identifier of the product), the Amazon price, the new price and the sales rank.

It is necessary to explain the difference between Amazon and new price. The former is the price of the product that is sold directly by Amazon, i.e. Amazon is not only the platform on which the sale takes place but is also the seller. The latter is the best (lowest) price that a third party sets for its products; these are not sold by Amazon but only use Amazon as a marketplace. Notably, Amazon prices are mostly determined by Amazon algorithms, while there is much more human discretion involved when third-party sellers sell their products (i.e. in new prices)

We would like to consider the quantities of the products sold to evaluate the effectiveness of price promotions. However, such data is not directly available from Amazon. Consequently, we need to rely on indirect measures of sales. Such a measure is the sales rank, which is calculated by Amazon based on the relative popularity of the product within the relevant category (e.g. in shoes). In most cases, the lower the sales rank, the higher the quantity of the product sold by the seller. However, the use of the sales rank comes with one considerable disadvantage. As a relative measure, we may observe an increase in sales rank, while at the same time the quantity of the product sold goes up. This could happen e.g. during the Christmas period, when the sales of all sellers are higher, but in our example, the sales of the competitors went up by more than ours. However, we would assume that for the best-selling items in our dataset the sales rank would be representative of the quantity sold. 


\section{Preliminary analysis}

I begin by demonstrating a number of required transformations of the data. The change in sales rank is calculated in the following way:

$$
\Delta \text { sales rank }=\frac{\text { new sales rank }- \text { old sales rank }}{\max (\text { new sales rank, old sales rank })}
$$

while the change in price is calculated in a more standard way as:

$$
\Delta \text { price }=\frac{\text { new price }- \text { old price }}{\text { old price }}
$$

The reason why we define the change in sales rank in such a way is that the conventional definition of percentage change would lead to significant jumps of the change in sales rank when the old sales rank is very low. Moreover, it would be asymmetric: a large increase in sales rank would happen more often that a large fall in sales rank, which is not desirable

\section{Hypothesis 1}

The first hypothesis that I am investigating is that the sales rank of a product improves upon a sufficiently large decline in price. Specifically, I begin by considering a one-day drop in the Amazon price that is larger than 20\%, which is considered to be the sufficiently large threshold for a sales promotion. The results are shown in the table

\begin{tabular}{|c|c|c|c|c|c|c|}
\hline changeinsales r k & Coef. & Std. Err. & $\mathrm{t}$ & $P>|t|$ & [95\% Conf. & Interval] \\
\hline \multicolumn{7}{|l|}{ dropinanazonp $\sim 20$} \\
\hline L1. & -.0066497 & .0071088 & -0.94 & 0.356 & -.0205828 & .0672833 \\
\hline _cons & .0098771 & .0005127 & 19.27 & 0.000 & .0088723 & .0108819 \\
\hline
\end{tabular}
below:

The result indicates that there is no statistically significant effect on the change in sales rank with respect to the change in Amazon price. One reason why this may be the case is that, as mentioned above, the setting of Amazon prices is done by an algorithm which rarely introduces steep reductions in prices, preferring to reduce the price gradually over time.

To consider the impact of more rapid price promotions, instead of Amazon price, I decided to focus on the new price, as more human discretion involved in setting them. 
In order to examine how effective price promotions are, I examined the change in sales rank when the drop in new price is more than $10 \%, 20 \%, 30 \%$ and $50 \%$, respectively.

\begin{tabular}{r|rrrrrr}
\hline changeinsalesr k & Coef. & Std. Err. & $t$ & $p>|t|$ & [95\% Conf. Interval] \\
\hline dropinnewpric 10 & $\mathbf{- 0 1 5 3 7 1 6}$ & .0048775 & $\mathbf{- 3 . 1 5}$ & $\mathbf{0 . 0 0 2}$ & $\mathbf{- . 0 2 4 9 3 1 4}$ & $\mathbf{- . 0 0 5 8 1 1 7}$ \\
_cons & .0100134 & .0005142 & $\mathbf{1 9 . 4 7}$ & $\mathbf{0 . 0 0 0}$ & $\mathbf{. 0 0 9 0 0 5 6}$ & $\mathbf{. 0 1 1 0 2 1 2}$
\end{tabular}

Figure 2: Regression of the change in sales rank on the drop in new price more than $10 \%$

\begin{tabular}{|r|rrrrrr} 
changeinsales r k & Coef. & Std. Err. & $t$ & $\mathrm{P}>\mid \mathrm{t}$ ] & [958 Conf. Interval] \\
\hline dropinnewpric 20 & -.0306396 & .0075055 & $\mathbf{- 4 . 0 8}$ & $\mathbf{0 . 0 0 0}$ & $\mathbf{- . 0 4 5 3 5 0 3}$ & -.015929 \\
_cons & .0099854 & .0005125 & 19.48 & 0.000 & .0089809 & .0109899 \\
\hline
\end{tabular}

Figure 3: Regression of the change in sales rank on the drop in new price more than $20 \%$

\begin{tabular}{|r|rrrrrr} 
changeinsalesr & Coef. & Std. Err. & $\mathrm{t}$ & $\mathrm{P}>\mid \mathrm{t}$ ] & [958 Conf. Interval] \\
\hline dropinnewpric 50 & -.0155357 & .0326842 & $\mathbf{- 0 . 4 8}$ & $\mathbf{0 . 6 3 5}$ & $\mathbf{- . 0 7 9 5 9 5 8}$ & .0485244 \\
_cons & .0098463 & .0005114 & $\mathbf{1 9 . 2 5}$ & $\mathbf{0 . 0 0 0}$ & .008844 & .0108487
\end{tabular}

Figure 4. Regression of the change in sales rank on the drop in new price more than $50 \%$

Except for the 50\% threshold, where the number of such large price promotions is limited, the $95 \%$ confidence intervals for the coefficient on the dummy variable corresponding to the drop in price are fully negative. This demonstrates that the sales rank may indeed decrease when there is a price promotion. Additionally, I find that the bigger the threshold for the price promotion, the more will the sales rank drop. In other words, while even small (>10\%) price promotions tend to increase sales of the product, the larger the size of the price promotion, the larger increase in sales is observed.

To sum up, not only does the sales rank drop when a sales promotion is organized, but the drop is larger when the price promotion is steeper. This can be explained by the 


\section{MANAGEMENT AND ECONOMICS}

fundamental demand curve as people tend to be more attracted by the product when there is a large drop in price.

\section{Hypothesis 2}

In order to examine the second hypothesis, which is the sales rank would remain lower after the period of the price promotion, some new variables are introduced. Besides the sales rank before the promotion, I also calculate the sales rank 30 days after the promotion as well as the difference between them.

We can tell from fact that the histogram is shifted away from zero to the left that the

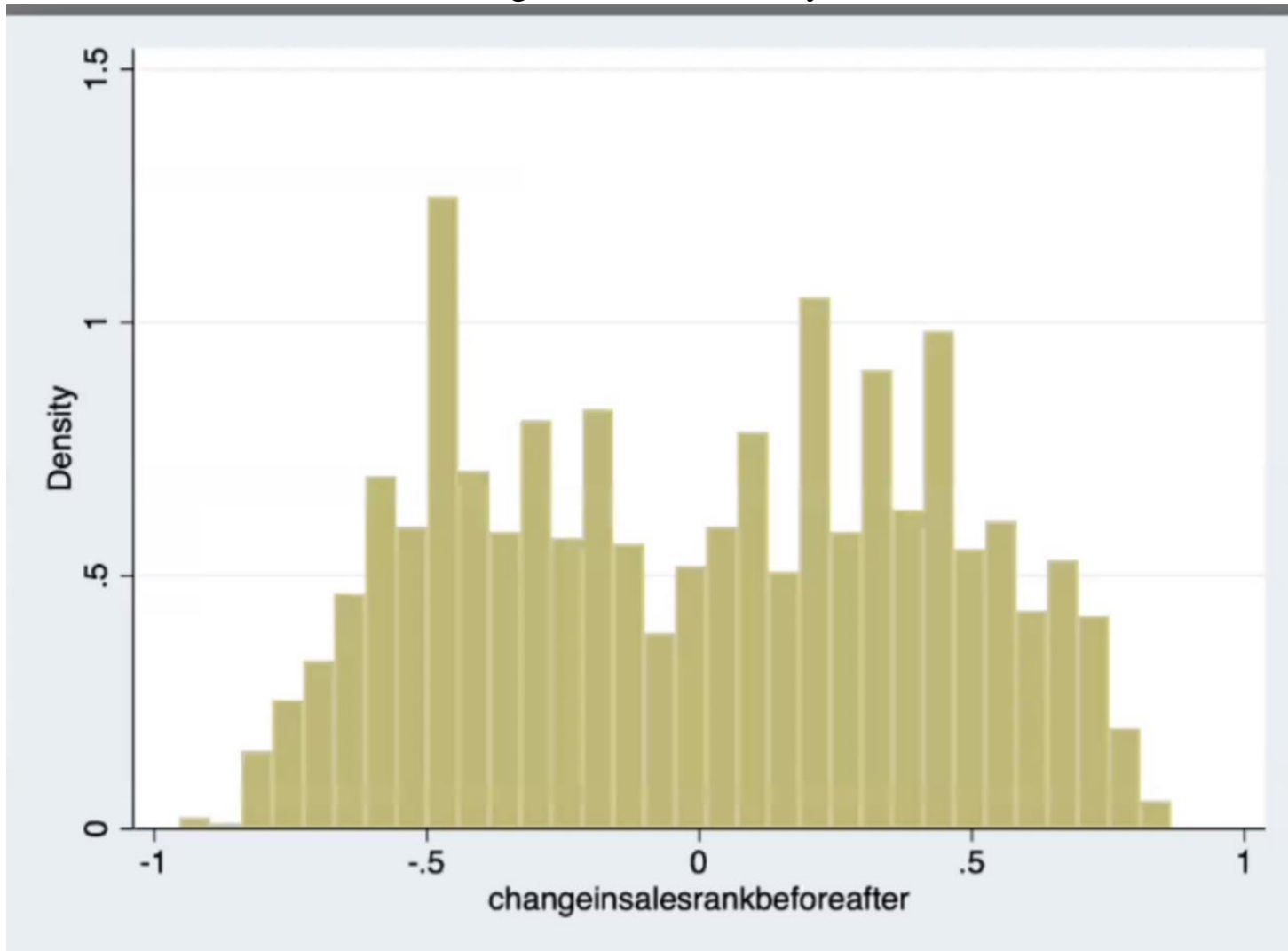

Figure 5: Histogram of the change in sales rank before and after the sales promotion when the drop in

sales rank tends to remain permanently lower following a price promotion of at least $20 \%$. Furthermore, I examined the sales rank before and after the drop in price is more than $10 \%, 20 \%, 30 \%$ and $40 \%$. 


\begin{tabular}{r|rrrrrr} 
Iropinnewpric 30 & -.0574571 & .0205745 & -2.79 & 0.005 & -.0977825 & -.0171318 \\
_cons & .032327 & .0007627 & 42.39 & 0.000 & .0308322 & .0338219 \\
\hline
\end{tabular}

All of the results are statistically significant which provide evidence in favor of our second hypothesis: following a price promotion, the sales rank will remain permanently lowered. It is universally acknowledged that a price promotion can be considered efficient only when it leads to a permanent increase in sales (or, equivalently, a permanent reduction in sales rank). Therefore, judging by this criterion, we can claim that sales promotions on Amazon are efficient.

Another result of the experiment is that, as before, the larger the sales promotion is, the larger the drop in sales rank remains after the promotion period. It is not uncommon that consumers are inclined to continue to buy the products further into the future (long after the promotion has finished) which they have bought and enjoyed during large price promotions.

\begin{tabular}{|c|c|c|c|c|c|c|}
\hline changeinsales r $\sim k$ & Coef. & Std. Err. & $\mathrm{t}$ & $P>|t|$ & [ $95 \%$ Conf. & Interval] \\
\hline dropinnewpric $\sim 10$ & -.0153716 & .0048775 & -3.15 & 0.002 & -.0249314 & -.0058117 \\
\hline _cons & .0100134 & .0005142 & 19.47 & 0.000 & .0090056 & .0110212 \\
\hline
\end{tabular}

Figure 6: Regression of the change in sales rank before and after on the drop in new price more than $10 \%$

\begin{tabular}{ll|lllllll}
- cons & .0324321 & .0007641 & .032 .45 & 0.000 & .0309346 & .0339291 \\
\hline
\end{tabular}

Figure 7: Regression of the change in sales rank before and after on the drop in new price more than $20 \%$

\section{$\underline{\text { Hypothesis } 3}$}

The last hypothesis is that the larger the price promotion, the less frequent it tends to take place. This is intuitively true since having large and frequent promotions may not 


\section{MANAGEMENT AND ECONOMICS}

contribute to the increase in revenues for producers. Again, for the reasons mentioned before, I focus on the new price rather than the Amazon price. I examined the frequencies of the price promotions corresponding to $10 \%, 20 \%, 30 \%$ and $40 \%$ drops in prices. The frequency of the price promotions was calculated as the total number of the sales promotions which are at least of the desired size divided by the amount of time for which we have the data for the specific product. The frequency was then normalized to give the number of promotions per year.

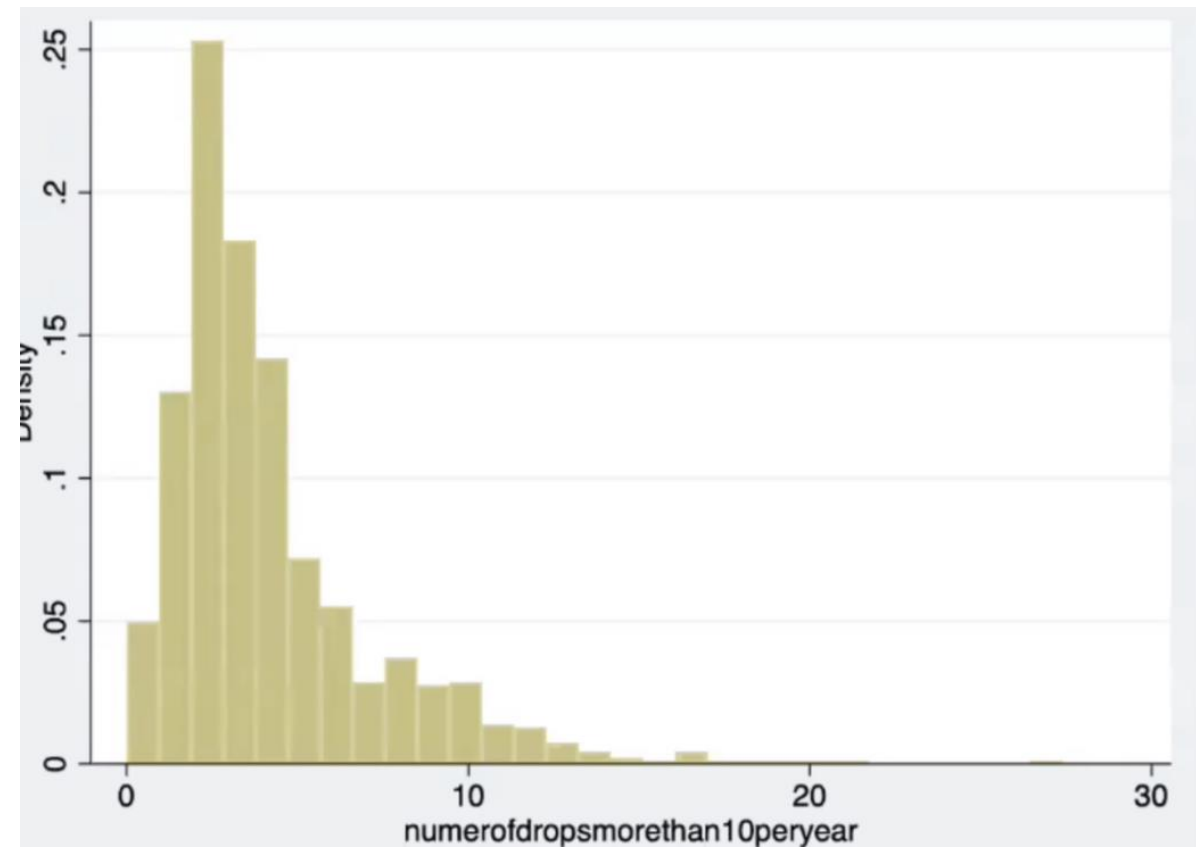

Figure 9: Histogram of the frequency of new price drops larger than $10 \%$ per year 
$3^{\text {rd }}$ International Conference On Research In

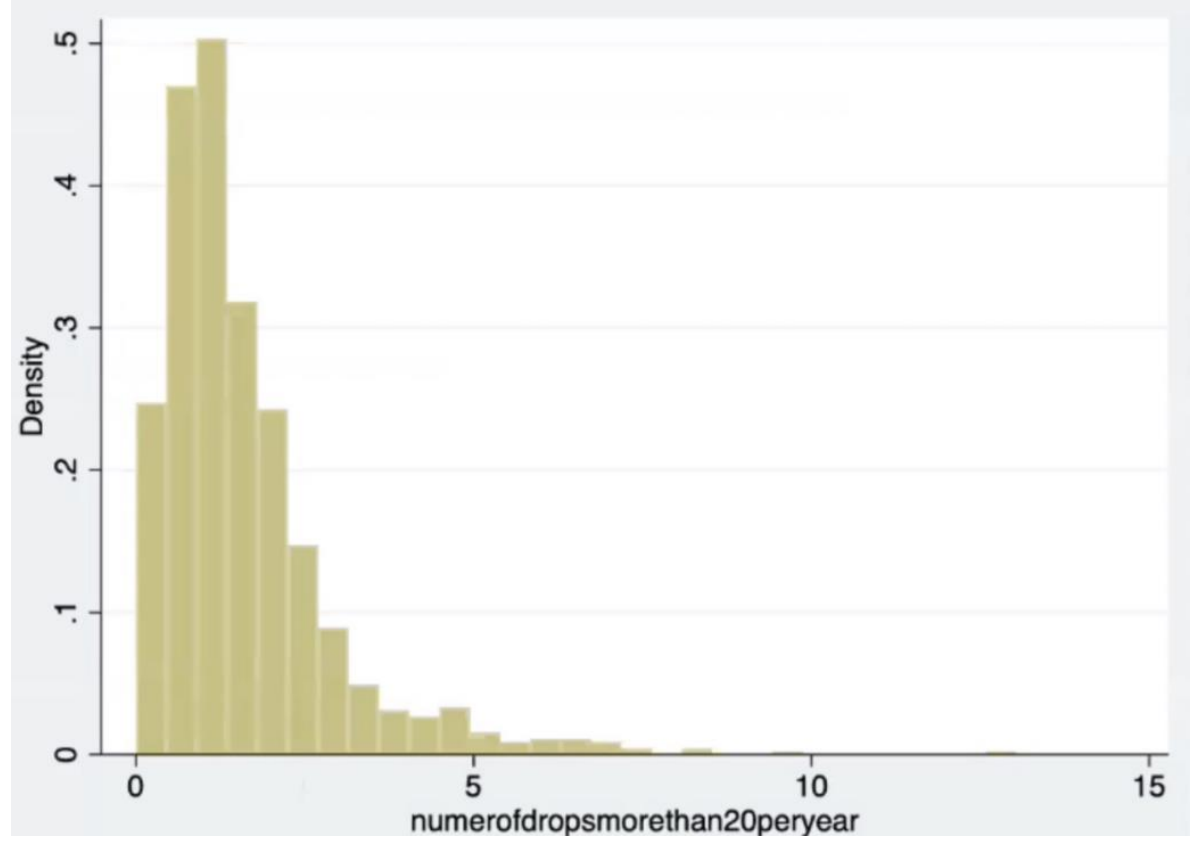

Figure 10: Histogram of the frequency of new price drops larger than $20 \%$ per year 
$3^{\text {rd }}$ International Conference On Research In

\section{MANAGEMENT AND ECONOMICS}

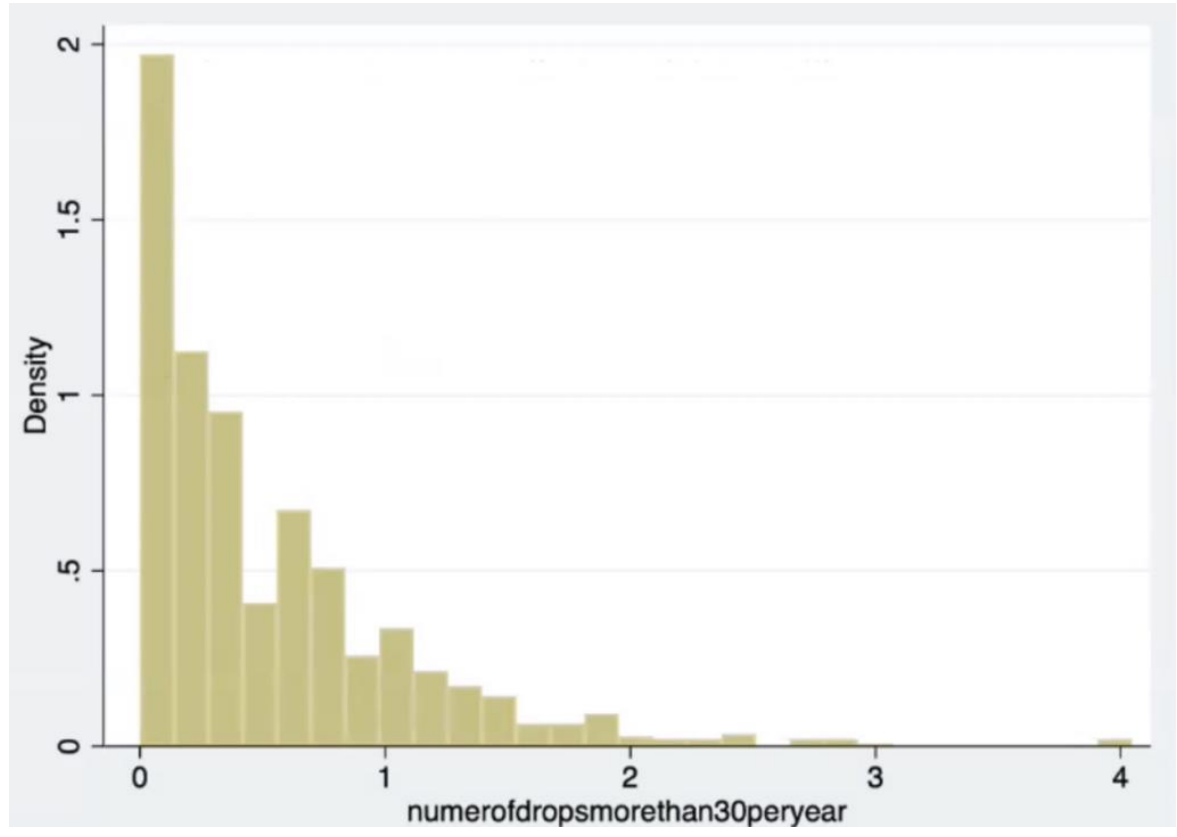

Figure 11: Histogram of the frequency of new price drops larger than $30 \%$ per year

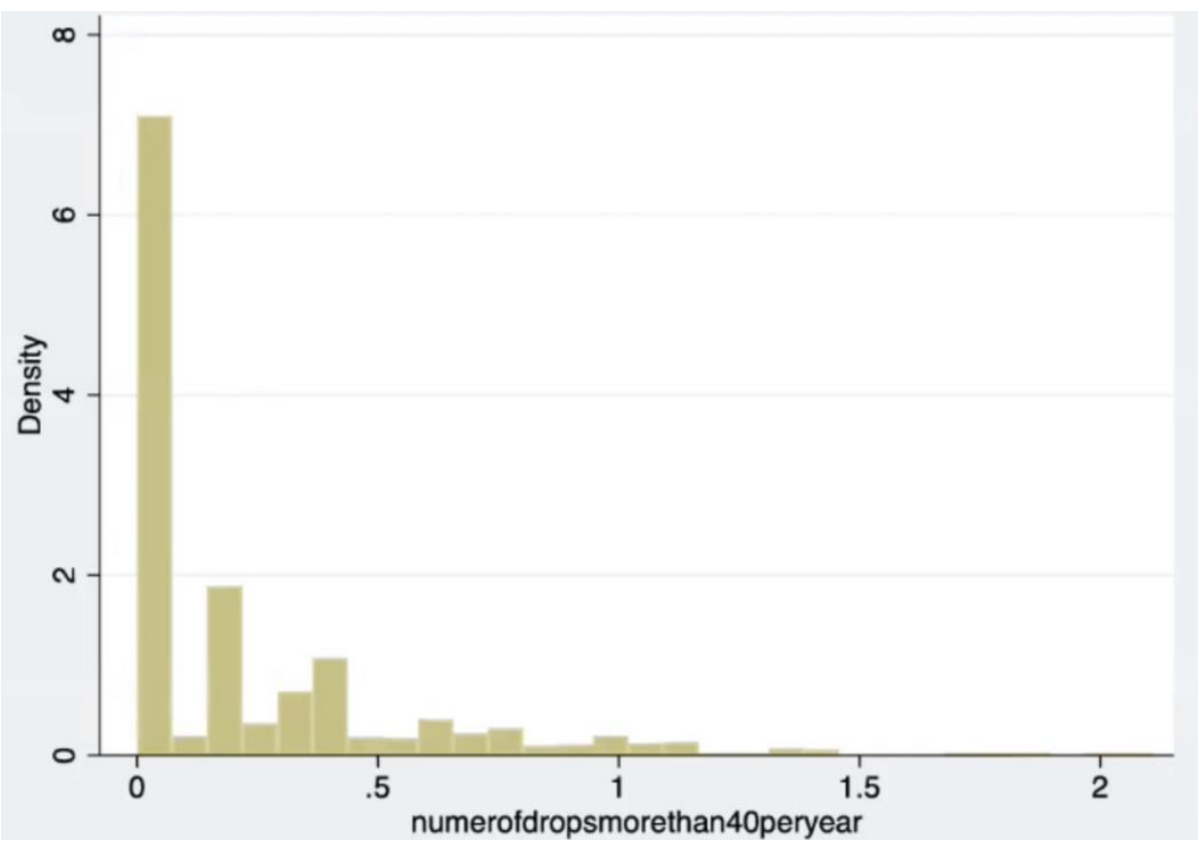


Figure 13:Summary statistics for the annual frequencies of price promotions of different magnitudes

Figure 12: Histogram of the frequency of new price drops larger than $40 \%$ per year

\begin{tabular}{r|rrrrr} 
Variable & Obs & Mean & Std. Dev. & Min & Max \\
\hline nunerofdr 20 & 1,000 & $\mathbf{2 . 6 0 9 7 9}$ & 2.149485 & 0 & 15.51129 \\
numerofdr 30 & 1,000 & 1.074395 & 1.034844 & 0 & 8.97909 \\
numerofdr 40 & 1,000 & .2867381 & .3746223 & 0 & 3.142681 \\
nu 40peryear & 1,000 & .231649 & .3392885 & 0 & 2.111861
\end{tabular}

The four histograms demonstrate that the larger the threshold we set for the price promotion, the less frequently such a promotion occurs. It can also be noted that we rarely observe price promotions that are larger than $40 \%$.

The table above indicates that if the price promotion is between $10 \%$ and $20 \%$, the number of such promotions is about 2.6 per year. This drops to 1.1 for the $20-30 \%$ range and 0.3 for the $30-40 \%$ range. If the price promotion is larger than $40 \%$, this number becomes only 0.2 , or in other words such promotions are not likely to take place. This seems to present a solid case for the hypothesis examined in this part of the paper.

\section{Conclusion}

Through a series of experiments, I verified three hypotheses related to the price promotions on Amazon. Firstly, the sales rank tends to drop when price promotions take place. Specifically, the larger the price promotion, the larger the drop in the sales rank would be. This is true because the majority of consumers are attracted by lower prices since they can get more advantages. Secondly, I prove that the sales rank would remain lower after the period of the price promotion. It is universally acknowledged that a price promotion can be considered as efficient only when it exerts permanent effect. This implies that producers having price promotions may contribute to the improvement of their revenues. Thirdly, it is verified that the larger the price promotion, the less frequently would it take place. Small price promotions applied to specific products may exert positive effect in terms of increasing of the revenue and improving of the brand 
image. However, applying large price promotions is very risky for the reason that producers' long-term revenues may suffer, and consumers might even begin to associate these continuous promotions with low quality.

There are still several limitations of my research that I would like to mention. This paper focuses on one specific product category (shoes), and the results do not need to generalize to other product categories. Moreover, it would be better to have data on the quantities sold as the sales rank is an imperfect indirect measure of these quantities and hence revenues. As explained before, the drop in sales rank does not necessarily mean an increase in the sellers' revenue. As a relative measure, we may observe an increase in sales rank, while at the same time the quantity of the product sold goes up. Moreover, this paper only considers the price promotions which happened over the span of one day, for example if a $30 \%$ promotion was subsequently increased to $60 \%$, we would record them as two $30 \%$ promotions rather than a $30 \%$ and a $60 \%$ discount. That is to say, there may be some inaccuracies in our experiment if the one specific promotion is continuously changing.

As for future research, these limitations could be removed to improve the accuracy of the experiments. Furthermore, future researchers could try to develop a deeper insight into different types of promotions which applied to different types of goods, and thus to examine their effectiveness. Additionally, they can also create a theoretical model with where the optimal retailing price can be found mathematically, and only then attempt to validate it empirically. 
$3^{\text {rd }}$ International Conference On Research In

\section{Bibliography}

Francis J. Mulhern and Daniel T. Padgett (1995). The relationship between retail price promotions and regular price purchases. The Journal of Marketing, 83-90.

Koen Waanders (2013). The effectiveness and consequences of price promotions. Master Communication Studies. Faculty of Behavioral Sciences University of Twente, 7-8.

Montaner, T., \& Pina, J. M. (2008). The effect of promotion type and benefit congruency on brand image. The Journal of Applied Business Research, 24(3), 15-28.

Tor Beltov, Steffen Jørgensen, Georges Zaccour (2006). Optimal retail price promotions. Anales de Estudios Economicos y Empresariales, Vol. XVI, 2006, 9-36. 